\title{
The Combined Effect of Temperature and Salinity on the Mechanical Behaviour of Well Cement
}

\author{
A. Subaha, V. Aarany and M.C.M. Nasvi
}

\begin{abstract}
Carbondioxide Capture and Storage (CCS) has been identified as the best measure to reduce the concentration of carbon dioxide in the atmosphere. Carbon dioxide expedites global warming. The captured carbon dioxide is stored in deep underground reservoirs using injection wells. The integrity of these wells needs to be ensured to have a durable carbon dioxide sequestration. Generally, the well cements of these underground wells lose their integrity primarily due to their degradation caused by aggressive curing temperatures and also due to the salinity conditions prevalent in the earth's down-hole. Therefore, the aim of this study was to ascertain the combined effect of the temperature and the salinity on the mechanical behavior of well cement. Sulphate resistant Class G cement samples were cured in various salinity concentrations ( 0 to $40 \%$ of $\mathrm{NaCl}$ of the weight of water) and at varying curing temperatures $\left(25,40,60\right.$ and $\left.80^{\circ} \mathrm{C}\right)$. The mechanical behavior of well cement under these varying salinity and temperature conditions was studied by analyzing its uniaxial compressive strength and the Young's modulus. Scanning Electron Microscope (SEM) images of degraded samples showed microstructural variations caused during the degradation process. EDX (Energy Dispersive X-Ray Spectroscopy) tests were also carried out to find out the proportion of chemical ions in the degraded cement samples. The test results revealed that the uniaxial compressive strength of the samples initially increases up to an optimum salinity of 10\% (by weight of water) and that it thereafter gradually decreases with increasing salinity. With the compressive strength varying with the curing temperature, the optimum temperature for 7 days of curing is found to be $40^{\circ} \mathrm{C}$ and that for 28 days of curing is found to be $60^{\circ} \mathrm{C}$. On the whole, OPC sulphate resistant well cement shows its optimum strength at $60^{\circ} \mathrm{C}$ and at a $\mathrm{NaCl}$ concentration of $10 \%$.
\end{abstract}

Keywords: Degradation, Salinity, Sequestration, Well cement

\section{Introduction}

The excessive anthropogenic emission of greenhouse gases accelerates global warming, which has evolved to be a major threat to our current as well as future generations.In the context of global warming, carbon dioxide $\left(\mathrm{CO}_{2}\right)$ plays a major role [11]. Hence, it has become vital to take measures to reduce the concentration of carbon dioxide in the earth's atmosphere. According to the statistical data of the World Meteorological Organization (WMO, 2015), the concentration of $\mathrm{CO}_{2}$ in 2015 was about 400 parts per million (ppm). This situation will become a challenge to the $21^{\text {st }}$ century engineers if life on the earth is to be sustained.

$\mathrm{CO}_{2}$ emissions mainly come from the increasing usage of coal powered plants and petroleum and from oil recovery. In this regard, green thinkers have recognized several mitigatory measures such as the improvement of the energy conversion efficiency of fossil fuels, shifting of energy production to low carbon sources and deep underground capture and storage of $\mathrm{CO}_{2}[5]$. Of all these measures, capturing and injecting $\mathrm{CO}_{2}$ deep underground has been found to be the most durable, economical, favorable and efficient means of reducing in the long term, the $\mathrm{CO}_{2}$ concentration in the atmosphere[6, 14].The captured $\mathrm{CO}_{2}$ is injected into deep reservoirs through bore hole wells. Sri Lanka is a developing country with a rising demand for electricity and increasing levels of power consumption. It is noteworthy to mention here that a coal power plant at Noraichcholai, Puttalam has been in operation in the country since 2011. A sour present electricity production is mainly dependent on hydro power, the expected scarcity of water in future will have a huge impact on the electricity production.

Miss. A.Subaha, Student Member of IESL, B.Sc.Eng.(Hons.) (Peradeniya), Department of Civil Engineering, University of Peradeniya.Email:subanan1992@gmail.com

Miss. V.Aarany, Student Member of IESL, B.Sc.Eng (Hons.)(Peradeniya), Department of Civil Engineering, University of Peradeniya. Email:aaraavwnn@gmail.com

Eng. (Dr.) M.C.M.Nasvi, AMIE(Sri Lanka),

B.Sc.Eng.(Hons.)(Peradeniya), Ph.D.(Monash), Senior Lecturer of Civil Engineering, Department of Civil

Engineering, University of Peradeniya.

Email:nasvimcm@pdn.ac.lk 
Hence, it may become necessary to shift to fossil fuel based coal power plants to fulfil our future energy requirements. This situation will lead to the production of high amounts of $\mathrm{CO}_{2}$ through the combustion of coal. In this backdrop, carbon capture and storage will be advantageous to Sri Lanka. Captured $\mathrm{CO}_{2}$ is stored in coal seams, depleted oil/gas reservoirs, deep saline aquifers and unminable coal beds [3].

In the wells through which $\mathrm{CO}_{2}$ is injected into underground reservoirs, there is a steel casing inserted at the center with cement pumped into the space between the casing and the formation. This is known as primary cementing [1]. Zonal isolation in these wells is ensured by the steel casing and primary cementing. Hence, the primary cement should have a high strength and it has to be highly resistant to $\mathrm{CO}_{2}$, and chemical degradation under adverse pressure, temperature and salinity conditions [4, 8]. The American Petroleum Institute (API) has recommended eight classes of well cement (Class A to F)based on their composition, acid resistance, bearable temperature etc. [13]. However, Class G cement is most preferable in deeper constructions2]. The major components of API Class G cement include $\mathrm{CaO}(64.7 \%$ by weight), $\mathrm{SiO}_{2}$ (22.9\% by weight), $\mathrm{Fe}_{2} \mathrm{O}_{3}$ (4.75\% by weight), $\mathrm{Al}_{2} \mathrm{O}_{3}$ (3.89 \% by weight) and $\mathrm{MgO}$ (1.8\% by weight)[13]. In $80 \%$ of the oilfield wells in the world Class G Portland cement has been used. Two of the most important factors affecting the integrity of well cement are the salinity and the temperature [5]. As we go down in the earth, due to the existence of various types of sub surface rock layers, the salinity varies in the range of $0-40 \%$ and the geothermal gradient is $30^{\circ} \mathrm{C} / \mathrm{km}$ [5]. Generally, the minimum depth of a well has to be about $800 \mathrm{~m}$ to ensure supercritical $\mathrm{CO}_{2}$ (Pressure = $7.3 \mathrm{MPa}$ and temperature $=31.8{ }^{\circ} \mathrm{C}$ ) [5]. The well cement in an injection/production well will be exposed to different salinity levels and this will affect the actual strength of the Portland cement. Therefore, the mechanical behaviour of well cement will depend on the salinity levels that exist during its curing.

Already, a few studies [7, 8, 9, 12, 16] focusing on the behaviour of well cement of oil wells under different temperature and salinity conditions have been done. Xingshan et al [16] have conducted a research using high sulphate resistance Class $G$ cement slurry with a w/c ratio of 0.44 to study the effect of salt content on the properties of cement slurry and on the hydration process. From the experimental findings, it has been noted that the compressive strength of cement increases with its curing time at all salinity levels, and this was due to the increased rate of hydration that prevails at higher temperatures. Furthermore, during a given period, the compressive strength will reduce as the salinity level is increased. This is due to the degradation of cement matrix because of its reaction with $\mathrm{NaCl}$. The salt content affects the $\mathrm{Ca}(\mathrm{OH})_{2}$ formation, and it also affects the interface between $\mathrm{Ca}(\mathrm{OH})_{2}$ and C-S-H. The effect of salt on C-S-H is due to the absorption of $\mathrm{NaCl}$ microcrystallites and $\mathrm{Na}$ through the surface of the fibrous structure.

Gowthaman et al [7] have found that the Ordinary Portland Cement (OPC) with sulphate resistance satisfies the requirements of API Class G cement. They have also concluded that OPC with sulphate resistance can be used instead of API Class G cement for the construction of injection wells. The strength and the Young's modulus of the OPC samples reduce with the increase in salinity levels due to the retardation of the hydration process at increased salinity levels. In addition, the strength and the Young's modulus of the cement samples cured in brine increase initially up to 14 days and then begin to decrease. This is because of the initial dominance of the hydration process although with ageing the samples get degraded due to the presence of $\mathrm{NaCl}$. This result can be further supported by observing the microstructural variations of the samples through a Scanning Electron Microscope (SEM) which will confirm that the above mentioned behavior of OPC is due to the reaction between the cement and $\mathrm{Cl}^{-}$ions in brine.

Lécolier et al [8] have investigated the physical and chemical effects of supercritical $\mathrm{CO}_{2}$ attack on well cement under different temperature $\left(40^{\circ} \mathrm{C}\right.$ and $\left.120^{\circ} \mathrm{C}\right)$ and pressure $(105$ bar and 140 bar) conditions. When considering the effects of different temperature conditions on the cement degradation caused by supercritical $\mathrm{CO}_{2}$, it was found that the rate of hydration was higher at higher temperatures Thus, the higher amounts of $\mathrm{Ca}(\mathrm{OH})_{2}$ and $\mathrm{C}-\mathrm{S}-\mathrm{H}$ that are produced at temperatures higher than $40^{\circ} \mathrm{C}$ may lead to the formation of higher amounts of smaller unhydrated grains. $\mathrm{CO}_{2}$ penetration was higher in wet supercritical $\mathrm{CO}_{2}$ than in $\mathrm{CO}_{2}$ saturated with brine, and this may be due to the higher solubility of $\mathrm{CO}_{2}$ in water than in brine. In contrast, the compressive strength was higher 
in wet $\mathrm{CO}_{2}$ than in $\mathrm{CO}_{2}$ saturated with brine due to the higher carbonation present in wet $\mathrm{CO}_{2}$. This carbonation can give a temporary strength but it cannot be guaranteed when there is long term exposure.

Nasvi et al [12] have compared the mechanical behavior of geopolymer and Class $\mathrm{G}$ cement at different down-hole temperatures $\left(20^{\circ} \mathrm{C}\right.$ to $90^{\circ} \mathrm{C}$ ). Two sets of samples had been made, one of Class G cement with a w/c ratio of 0.4 and the other of geopolymer with an alkaline liquid to fly ash ratio of 0.4 with each sample having a diameter of $50 \mathrm{~mm}$ and a height of $100 \mathrm{~mm}$. The optimum curing temperature of both Class G cement and geopolymer for the peak strength had been found to lie between $55-60{ }^{\circ} \mathrm{C}$. The compressive strength of geopolymer increases with the increase of temperature, while that of Class G cement shows an increment only initially with a reduction near $80^{\circ} \mathrm{C}$. At lower curing temperatures, Class $\mathrm{G}$ cement is stiffer compared to geopolymer, and at elevated temperatures geopolymer becomes stiffer than Class G cement. They have therefore concluded that Class $\mathrm{G}$ cement will be a good option at depths under $1 \mathrm{~km}$ (assuming a geothermal gradient of $30{ }^{\circ} \mathrm{C} / \mathrm{km}$ ), while geopolymer will be best suited at depths above $1 \mathrm{~km}$, where the temperature is expected to be above $40^{\circ} \mathrm{C}$.

Mojtaba et al [9] have done a study to find out the optimum safety depth for the injection of Class $\mathrm{G}$ cement. Cement slurry was made with Class G cement, water and additives (Calcium Chloride as the accelerator and D-013 as the retarder) with a water to cement ratio of 0.5 . Samples were cured for 24 hours and 48 hours under various combinations of pressure (51.7 $\mathrm{MPa})$ and temperature $\left(121^{\circ} \mathrm{C}-149 \quad{ }^{\circ} \mathrm{C}\right)$ conditions. Their findings revealed that when the pressure and temperature are increased, the early-age compressive strength of the Class G cement also increases. The rate of increment is higher for higher pressures and temperatures. The early-age compressive strength helps to reduce gas migration through the cement columns in the oil wells. The faster development of the early-age compressive strength can lead to a reduction in the transition phase time. When pressure and temperature are further increased, the compressive strength reduces significantly due to the instability of $\mathrm{CSH}$ at temperatures above $110^{\circ} \mathrm{C}$.

The effect of temperature and pressure on the behavior of well cement has also been studied by Barbara et al [4]. In this research, Class $\mathrm{H}$
Portland cement with a water cement ratio of 0.38 had been mixed in accordance with the API Recommended Practice 10B. Thereafter, the cement samples had been cured for 28 days in a brine solution in high pressure vessels and the cement had been allowed to be cured under four different pressure and temperature conditions $\left(22{ }^{\circ} \mathrm{C}, 50{ }^{\circ} \mathrm{C}, 0.1 \mathrm{MPa}\right.$ and 30.3 $\mathrm{MPa})$. Their findings have revealed that the solubility of $\mathrm{Ca}(\mathrm{OH})_{2}(\mathrm{~s})$ decreases with increasing temperature. At increased pressures, the dependence of $\mathrm{Ca}(\mathrm{OH})_{2}(\mathrm{~s})$ on the temperature is higher. Both the curing temperature and the curing pressure can have a huge impact on the physical properties of hydrated cement. However to date, there have been no studies done focussing on the behaviour of the combined effect of temperature and salinity on the mechanical behaviour of well cement. Hence, the main aim of this research was to study the combined effect of salinity and temperature on the mechanical behaviour of well cement.

\section{Research Methodology}

A series of experiments were conducted with different salinity levels $(0 \%, 10 \%, 20 \%, 30 \%$ and $40 \%$ by weight of water) and temperatures $\left(25^{\circ} \mathrm{C}, 40^{\circ} \mathrm{C}, 60^{\circ} \mathrm{C}\right.$ and $\left.80^{\circ} \mathrm{C}\right)$. In this study, sulphate resistance Portland cement samples having a composition similar to Class $\mathrm{G}$ cement samples were used as the well cement. Table 1 shows the composition of sulphate resistance cement.

Table 1 - Composition of sulphate resistance cement used in the study [8].

\begin{tabular}{|c|c|c|}
\hline Constituents & $\begin{array}{l}\text { OPC based well } \\
\text { cement (\%) }\end{array}$ & $\begin{array}{l}\text { API Class G } \\
\text { cement }(\%)\end{array}$ \\
\hline $\mathrm{CaO}$ & 64.40 & 64.7 \\
\hline $\mathrm{SiO}_{2}$ & 20.38 & 22.91 \\
\hline $\mathrm{Fe}_{2} \mathrm{O}_{3}$ & 3.26 & 4.75 \\
\hline $\mathrm{Al}_{2} \mathrm{O}_{3}$ & 4.79 & 3.89 \\
\hline $\mathrm{MgO}_{5}$ & 0.98 & 1.8 \\
\hline $\mathrm{SO}_{3}$ & 2.21 & 0.74 \\
\hline $\mathrm{K}_{2} \mathrm{O}$ & 0.04 & 0.64 \\
\hline $\mathrm{Na}_{2} \mathrm{O}$ & - & 0.1 \\
\hline
\end{tabular}

It can be seen that sulphate resistance cement has a composition similar to that of Class $G$ cement and hence the former can be used in place of Class G cement. Gowthaman et al [7] 
have also confirmed that sulphate resistance cement can be used instead of Class G cement.

Neat well cement samples (without any aggregate) were prepared with a diameter of 40 $\mathrm{mm}$ and a height $80 \mathrm{~mm}$ using PVC moulds. The water/cement $(\mathrm{w} / \mathrm{c})$ ratio used in the sample preparation was 0.44 as it has been found that this is the optimum water cement ratio that will get the maximum strength $[8,10$, 11]. The samples were left at room temperature $\left(25{ }^{\circ} \mathrm{C}\right)$ for 12 hours. Thereafter, they were cured at different temperatures and salinity levels for a period of 7 and 28 days. During their curing, only the top surface of the samples were covered by polythene (as shown in Figure 1 ), to prevent any moisture loss.

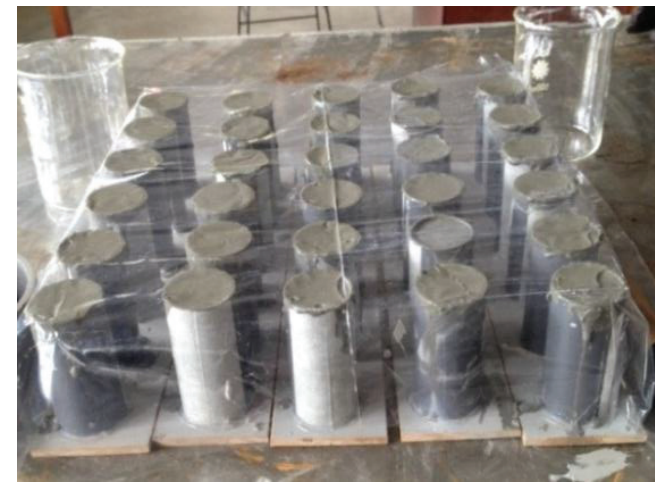

Figure 1 - Casted cement samples for curing

Saline water was prepared by mixing table salt and tap water in the proportions of $0 \%, 10 \%$, $20 \%, 30 \%$ and $40 \%$ by weight of water. Samples were allowed to cure in different salinity concentrations and at different temperatures for a period of 7 and 28 days. Control samples that were kept at the relevant temperature without being brine cured were used to compare the results. For each specific condition, three samples were tested to ensure reproducibility.
Hence, a total of 120 samples had to be prepared for this research study. The uniaxial compression strength testing machine (Avery with a capacity of $60,000 \mathrm{lb}$ ) available at the Materials Laboratory, Faculty of Engineering, University of Peradeniya was used to determine the uniaxial compressive strength of the samples. The samples were placed in the bottom platen and the load was applied gradually with a stress controlled loading rate of $0.2 \mathrm{MPa} / \mathrm{sec}$ until the samples failed. A Scanning Electron Microscope (SEM) was used to study the microstructural variation of cement under different temperature and salinity conditions. SEM and EDX tests were conducted at the Department of Geology, Faculty of Science, University of Peradeniya.

\section{Results and Discussion}

The variation of the Uniaxial Compressive Strength (UCS) at varying salinity levels for 7 and 28 days of curing are shown in Figures 2 and 3 respectively. The variation of the Young's Modulus is shown in Figures 4 and 5. The standard deviation of the test results is in the range of 0 to $7 \mathrm{MPa}$. According to Figures 2 and 3 , the compressive strength of sulphate resistance cement samples initially increase with increasing salinity up to a $\mathrm{NaCl}$ content of $10 \%$ (by weight of water) and then it starts to decrease towards $40 \%$ (by weight of water) of $\mathrm{NaCl}$ content. The initial increment in UCS is due to the absorption of $\mathrm{NaCl}$ microcrystallites through the surface of the fibrous structure (on the surface of the C-S-H ) and this may act as a bridge between the two C-S-H particles, but will not contribute to the structure of C-S-H [15]. 


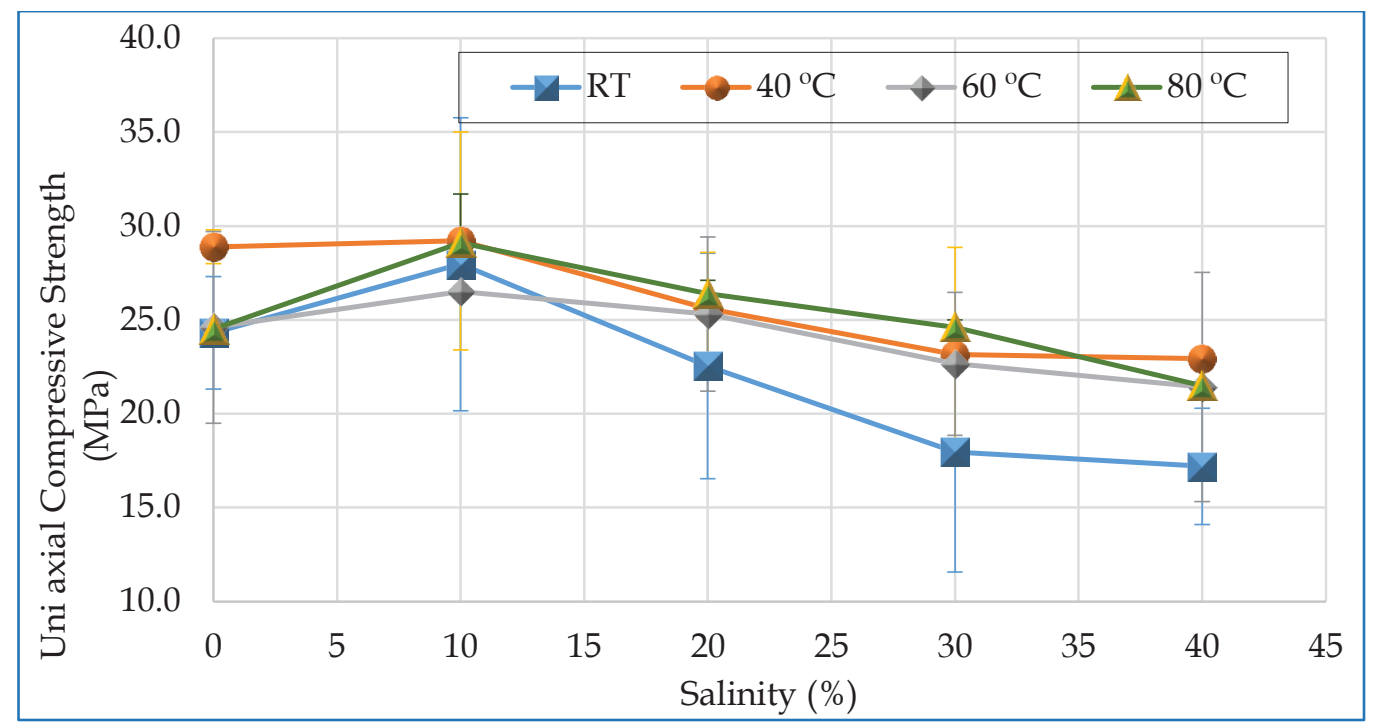

Figure 2 - Variation of the compressive strength with varying salinity levels during7 days of curing

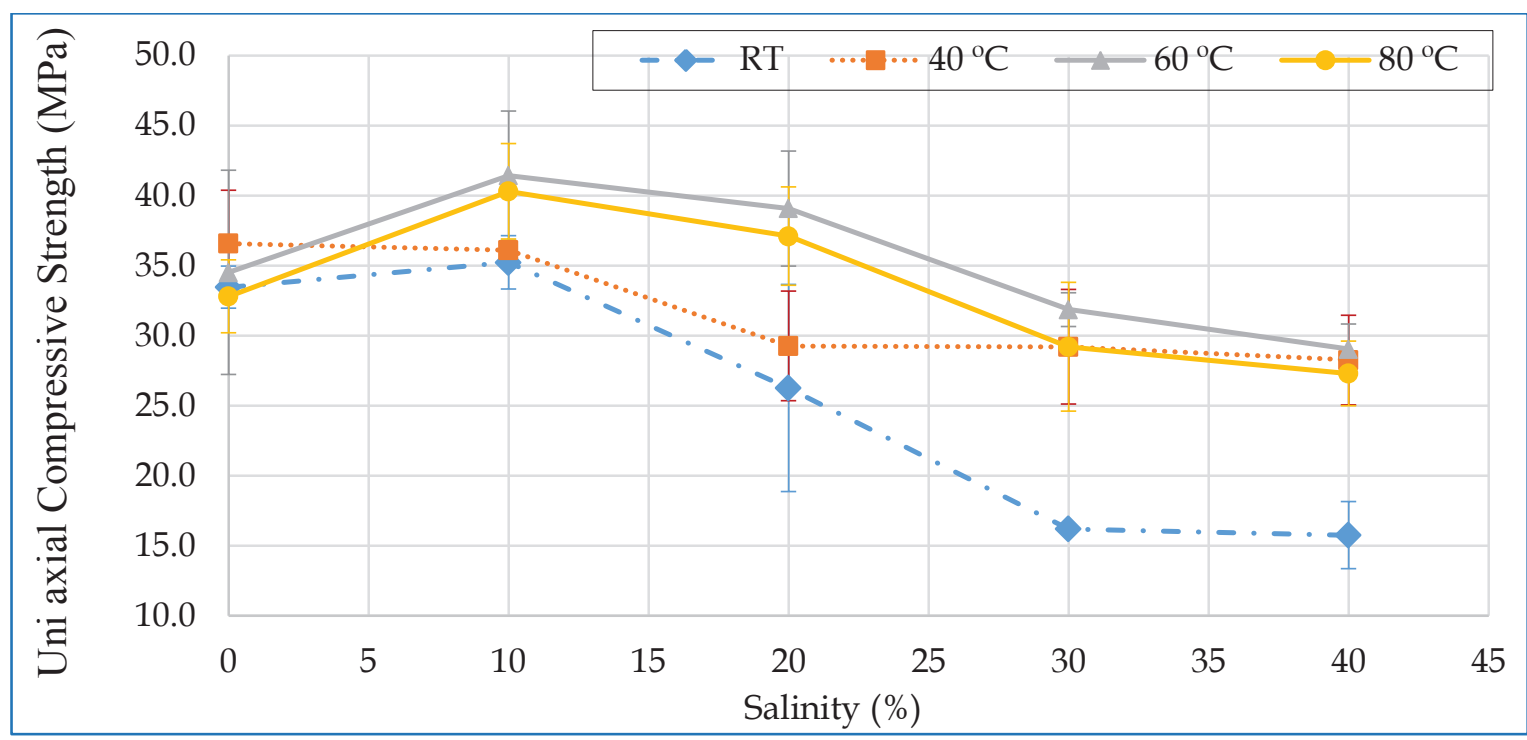

Figure 3 - Variation of the uniaxial compressive strength with varying salinity levels during 28 days of curing

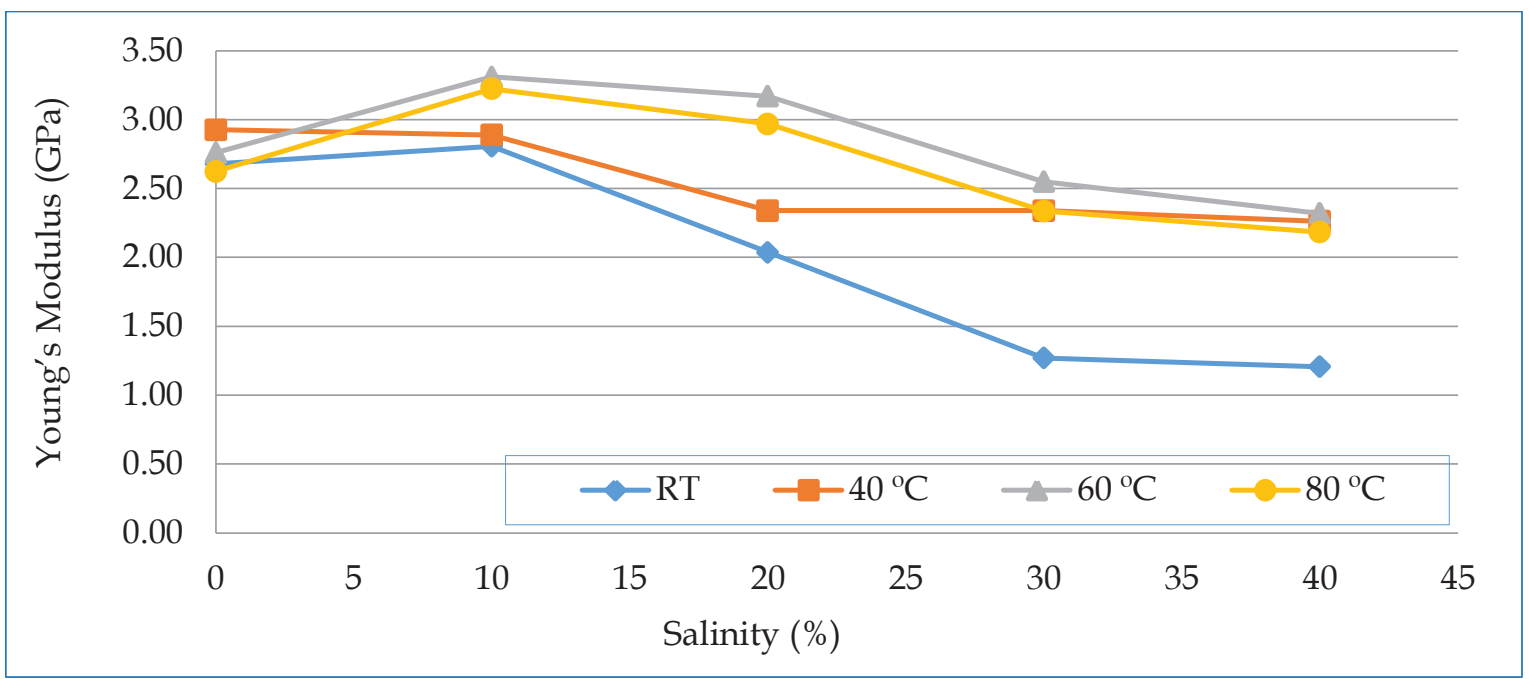

Figure 4 - Variation of Young's Modulus with varying salinity levels during 7 days of curing 


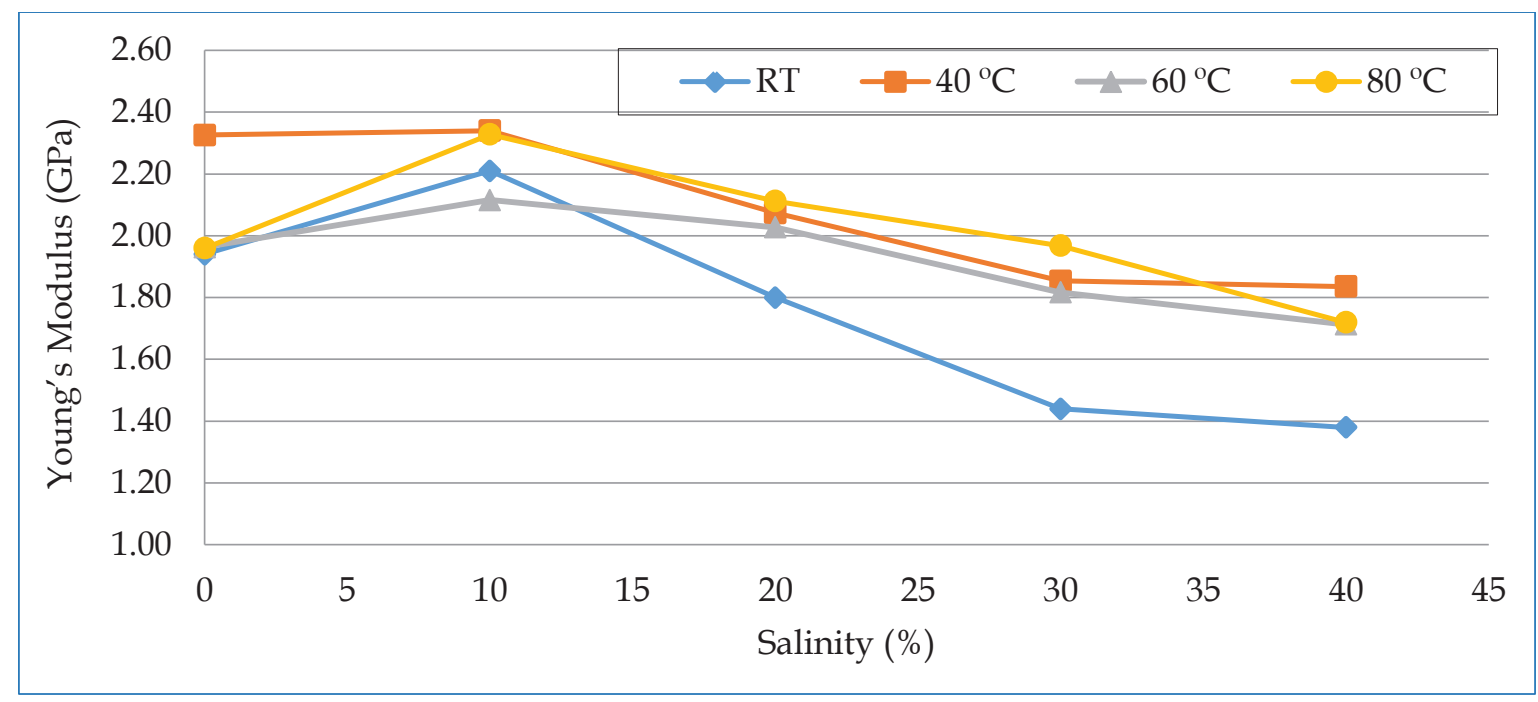

Figure 5 - Variation of Young's Modulus with varying salinity levels during 28 days of curing

At higher salt concentrations, the strength decreases as a result of $\mathrm{Ca}^{2+}$ ions in C-S-H getting precipitated with $\mathrm{Cl}^{-}$ions of $\mathrm{NaCl}$. A portion of $\mathrm{NaCl}$ is dispersed in C-S-H and $\mathrm{Ca}(\mathrm{OH})_{2}$ in the form of a solid solution or microcrystallite precipitation [16]. Also, at higher salt concentrations, $\mathrm{Cl}^{-}$will penetrate into cement and replace the $\mathrm{OH}^{-}$ion, and this $\mathrm{OH}^{-}$ion will pass the solution and form an insoluble hydroxide $\left[\mathrm{Ca}(\mathrm{OH})_{2}\right]$ by reacting with the $\mathrm{Ca}^{2+}$ ion in the unreacted cement matrix [15], and thus the rate of hydration will decrease. The optimum salinity for both curing conditions is $10 \%$ (by weight of water) of the $\mathrm{NaCl}$ content.

Figures 6 and 7 show the variation of the uniaxial compressive strength with varying temperature for 7 and 28 days of curing, respectively. The variation of Young's modulus also follows a variation similar to that of UCS, as shown in Figures 8 and 9. According to
Figures 6 and 7, the compressive strength of the samples cured in different salinity concentrations first increases and thereafter begins to decrease with increasing temperature. For a 7 day curing period, the strength increases up to $40{ }^{\circ} \mathrm{C}$ and attains the peak strength and then starts decreasing towards 80 ${ }^{\circ} \mathrm{C}$. For a 28 day curing period, the peakstreng this at $60^{\circ} \mathrm{C}$. According to previous studies [12], the optimum temperature for Class $\mathrm{G}$ cement is between $50-60{ }^{\circ} \mathrm{C}$, and this finding is therefore consistent with the findings of the previous studies. With the increase of temperature, the rate of hydration increases, and this leads to an initial increase in strength. The reduction of the strength beyond the optimum temperature is due to the reduction of the solubility of $\mathrm{Ca}(\mathrm{OH})_{2}(\mathrm{~s})$ with increasing temperature. This decrease in solubility decelerates the hydration process leading to strength reduction [4]. The strength reduction is also due to the loss of silica at higher temperatures[11].

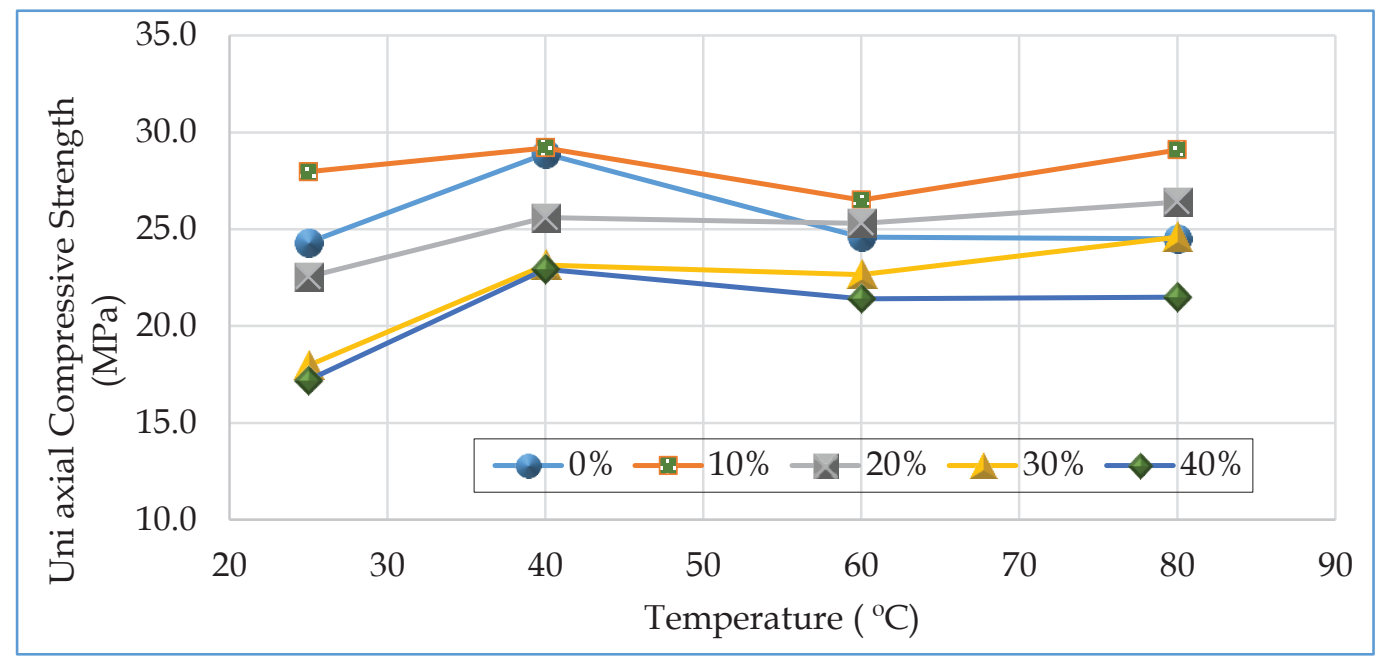

Figure 6 - Variation of the uniaxial compressive strength with temperatures during 7 days of curing 


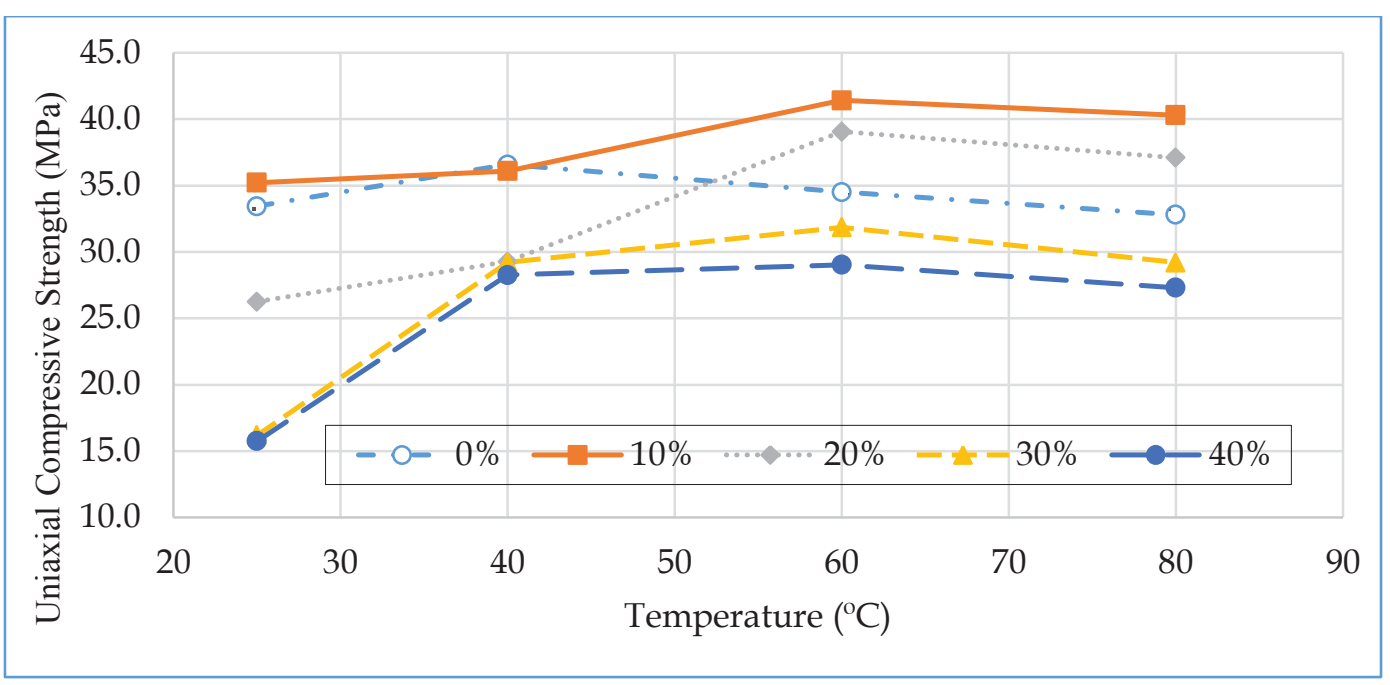

Figure 7 - Variation of the uniaxial compressive strength with temperatures during 28 days of curing

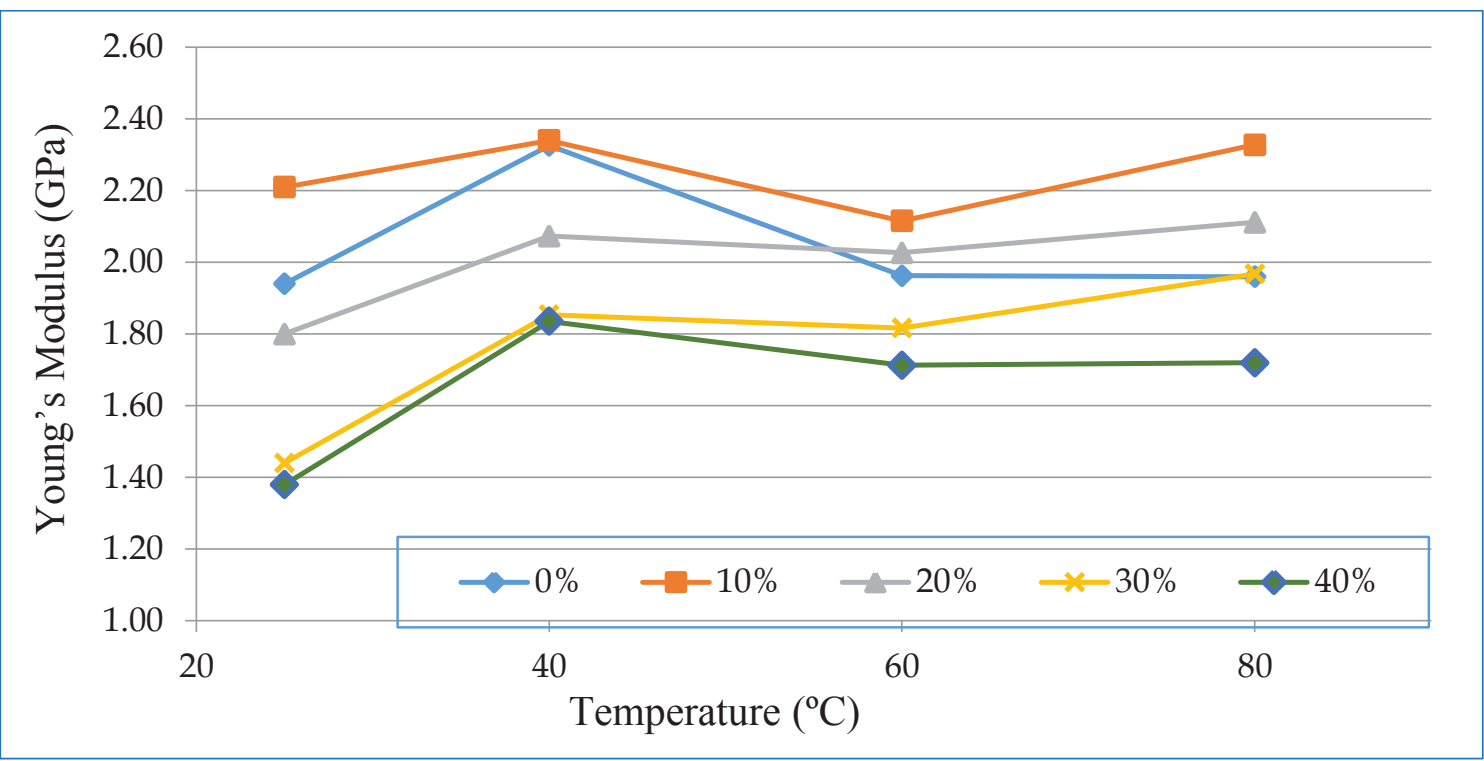

Figure 8 - Variation of the Young's Modulus with varying temperatures during 7 days of curing

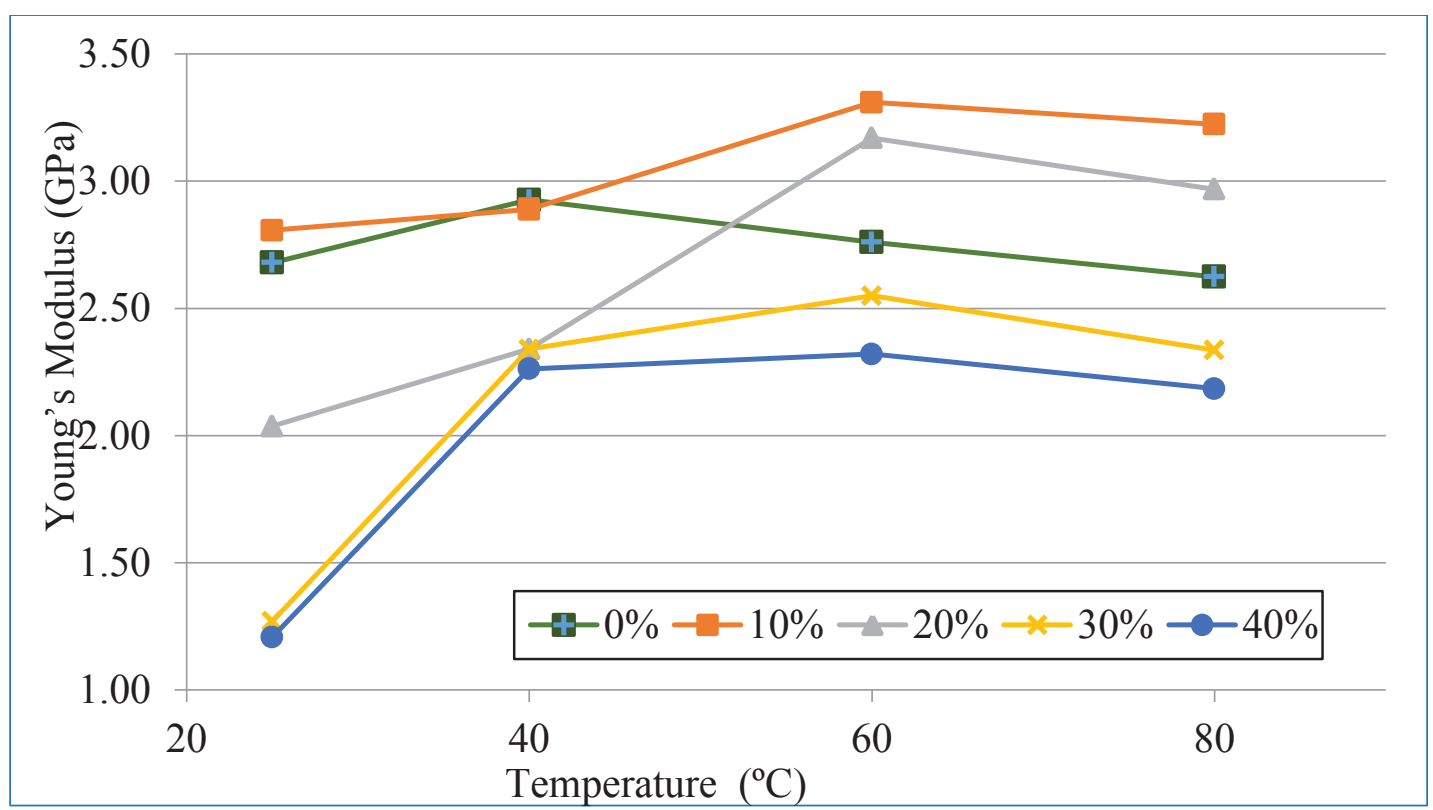

Figure 9 - Variation of Young's Modulus with varying temperature for 28 days of curing. 
An attempt was made to identify the microstructural changes in samples under various salinity and temperature conditions through the Scanning Electron Microscopic (SEM) test. This test was conducted using the Oxford EVO LS15 SEM apparatus (Figure 10). Table 2 shows the overall SEM results of the tests. According to Table 2, an ample amount of uniformly distributed $\mathrm{CSH}-\mathrm{NaCl}$ complex was found in the sample cured in $10 \% \mathrm{NaCl}$ compared to the samples cured in $0 \%$ and $30 \% \mathrm{NaCl}$.
This is the main reason for the high UCS values obtained with $10 \% \mathrm{NaCl}$ concentration. Energy-Dispersive X-Ray Spectroscopy (EDX) analysis was also done to trace $\mathrm{NaCl}$ in the cement samples. Figure 11 shows an image of a cement sample cured in $30 \% \mathrm{NaCl}$ (by weight of water) for 28 days at $80^{\circ} \mathrm{C}$. The white colour crystals are the $\mathrm{NaCl}$ solid deposits. It shows that when aging in a brine solution, the cement samples get degraded as the $\mathrm{NaCl}$ particles penetrate through them and get deposited in between the samples.

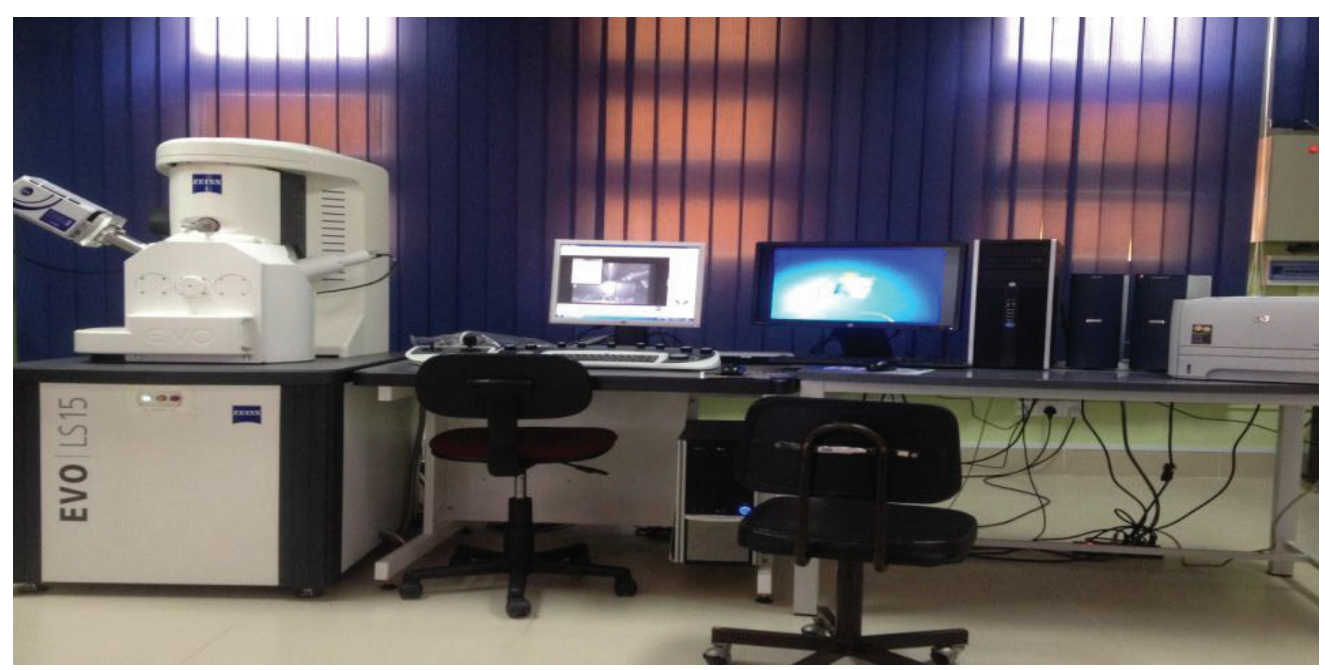

Figure 10 - SEM apparatus (Oxford EVO LS15 SEM apparatus)

Table 2 - SEM image analysis of the cement samples

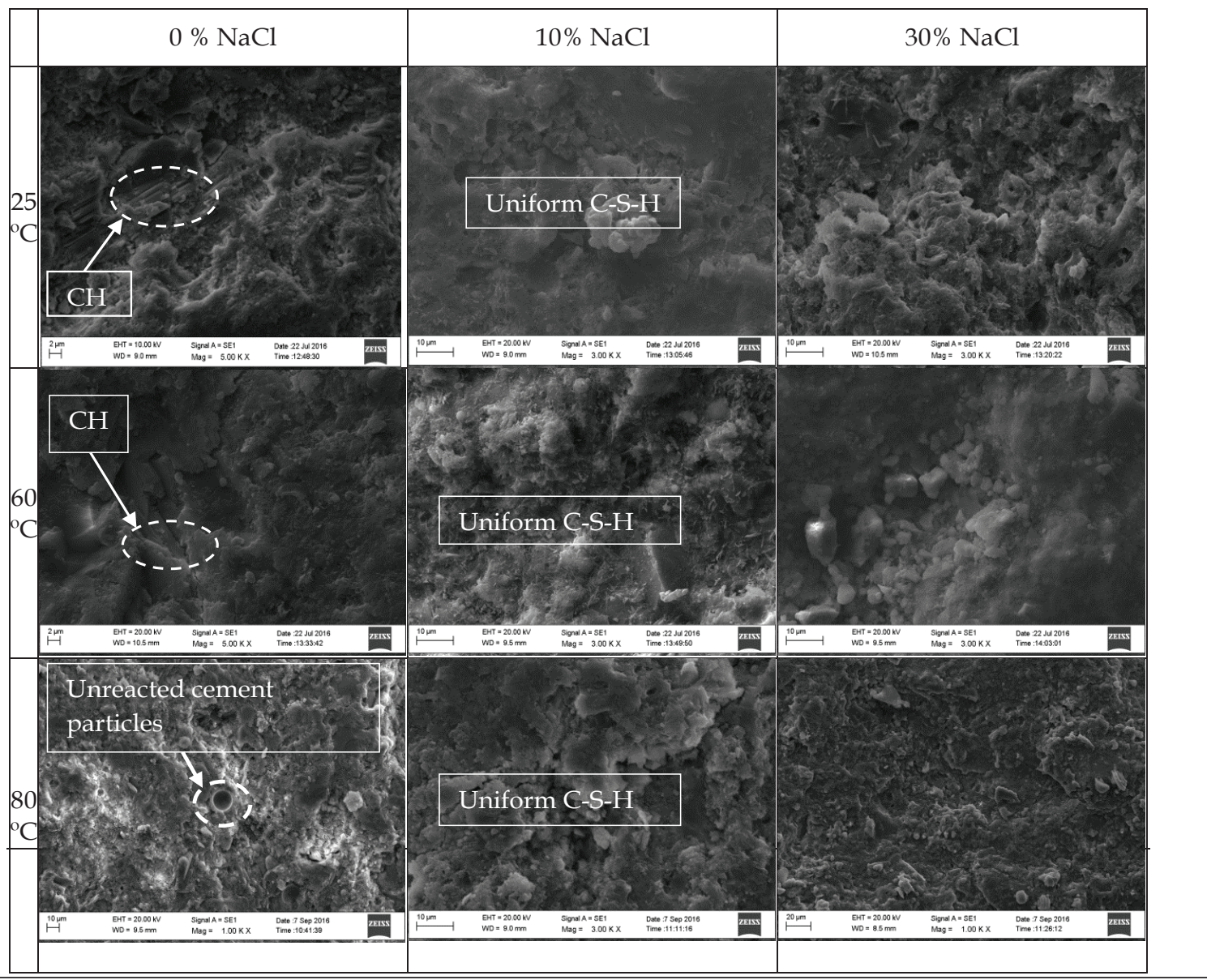



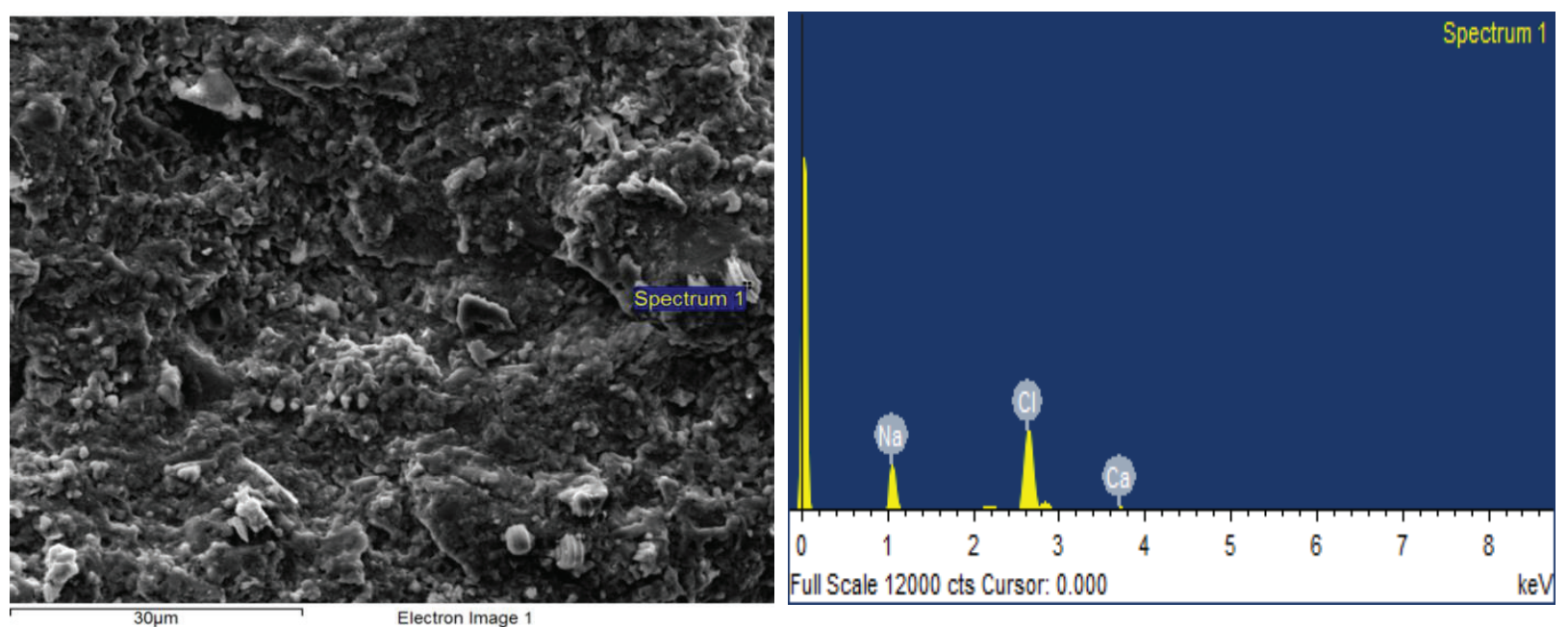

Figure 11 - SEM and EDX images of the sample that was cured in $30 \% \mathrm{NaCl}$ (by weight of water) for 28 days at $80^{\circ} \mathrm{C}$.

\section{Conclusion}

An experimental program was conducted to study the combined effect of temperature $\left(\mathrm{RT}: 25^{\circ} \mathrm{C}, \quad 40^{\circ} \mathrm{C}\right.$ and $\left.80^{\circ} \mathrm{C}\right)$ and salinity $(0-40 \% \mathrm{NaCl})$ on the mechanical behavior of well cement. As the salinity is increased, the compressive strength initially increases up to $10 \% \mathrm{NaCl}$ and thereafter it starts to decrease. The initial increase in the strength is due to the absorption of $\mathrm{NaCl}$ through the surface of the fibrous structure, and the reduction beyond the optimum is due to the delay in the hydration process, as $\mathrm{Cl}^{-}$penetrates to the cement leaching $\mathrm{Ca}^{2+}$ out of the cement matrix. The compressive strength also initially increases with temperature and thereafter decreases. The initial increase is due to the increased rate of hydration. At elevated temperatures, the C-S-H molecules become denser, and hence they cannot fill up the capillary pore spaces effectively. Hence, the strength decreases with increasing temperature. The Young's modulus also has a variation similar to that of the uniaxial compressive strength. On the whole, the OPC sulphate resistant well cement shows its optimum strength at $10 \% \mathrm{NaCl}$ and $60^{\circ} \mathrm{C}$.

The results obtained from the compressive strength and Young's modulus were further supported by observing the microstructural variations using a Scanning Electron Microscope (SEM) and an Energy Dispersive XRay Spectroscopy(EDX) analysis. The results obtained from the SEM and EDX analyses indicate that the above mentioned behaviour of the OPC is due to the effects of $\mathrm{NaCl}$ brine present.

\section{References}

1. Andrew, D., Mileva, R., George, S., (2005). Degradation of Well Cements Exposed to Carbonated Brine, Fourth Annual Conference on Carbon Capture and Sequestration DOE/NETL.

2. Arina, B. S., Sonny I. (2012). Effects of Pressure and Temperature on Well Cement Degradation by Supercritical $\mathrm{CO}_{2}$, International Journal of Engineering \& Technology IJET-IJENS, 10 (04): 53-61.

3. Bachu, S., (2000). Sequestration of $\mathrm{CO}_{2}$ in Geological Media: Criteria and Approach for Site Selection in Response to Climate Change, Energy Conversion and Management, 41 (9): 953-970.

4. Barbara, G., Kutchko, B. R., Strazisar, D. A., Dzombak, R., Lowry, Niels T. (2007). Degradation of Well Cement by $\mathrm{CO}_{2}$ under Geologic Sequestration Conditions, Environ. Sci. Technol.

5. Barlet, G., Rimmele, G., Porcherie, O., Quisel, N., Desroches, J., (2009). A Solution against Well Cement Degradation under $\mathrm{CO}_{2}$ Geological Storage Environment, International journal of Greenhouse Gas Control 3:206-216.

6. Gielen, D., (2003). The Future Role of $\mathrm{CO}_{2}$ Capture and Storage, Results of the IEA-ETP model, EET/2003/04, Paris.

7. Gowthaman, S., Krishnya, S., and Nasvi, M. C. M., (2016), Effect of Salinity on Mechanical Behaviour of Well Cement, Application to Carbon Capture and Storage Wells, The Institution of Engineers Sri Lanka (IESL) journal

8. Lécolier, E., Rivereau, A., Le Saoût, G., Audibert, H., (2007). Durability of Hardened Portland 
Cement Paste used for oilwellementing, Oil \& Gas Science and Technology Rev. IFP, 62 No. 3: 335-345.

9. Mojtaba, L., Behzad, Z., Amin, K., (2010). EarlyAge Compressive Strength Assessment of Oil Well Class G Cement due to Borehole Pressure and Temperature Changes, Journal of American Science.

10. Nadine, N., Lecolier, E., Aouad, G., Rivereau, A., Damidot, D., Chimie, C. R., Effect of Curing Conditions on Oilwell Cement Paste Behaviour during Leaching. Experimental and Modelling Approaches. 12: 511-520, 2009.

11. Nasvi, M. C. M., Ranjith, P. G., Sanjayan J.,(2012). Mechanical Properties of Geopolymer Cement in Brine, 7th Asian Rock Mechanics Symposium.

12. Nasvi, M. C. M., Ranjith, P. G., Sanjayan, J., (2012). Comparison of Mechanical Behaviors of Geopolymer and Class G Cement as Well Cement at different Curing Temperatures for Geological Sequestration of Carbondioxide, American Rock Mechanics Association.

13. Runar, N. R., (2010). Well Design and Well Integrity, Wabamun Area $\mathrm{CO}_{2}$ Sequestration Project (Wasp).

14. Sarmiento, J. L., Gruber N. (2002). Sinks for anthropogenic carbon, Physics Today:30-36.

15. Suzuki, K., Nishikawa, T., Ikenaga, H., and Ito, S., (1986). Effect of $\mathrm{NaCl}$ or $\mathrm{NaOH}$ on the formation of C-S-H, Nagoya Institute of Technology, Nagoya, Japan, Cement and Concrete research. Vol. 16: 333-340.

16. Xingshan, Z., Xian, L., Mingijiang, H., Ying Z., (1996) The Hydration of Saline Oil Well Cement, Research Institute of Engineering Technology of China, National Petroleum Corporation. 